\title{
Design of mooring system for a floating production storage and offloading (FPSO) terminal
}

\author{
Umana, Emediong Christopher ${ }^{1,}{ }^{*}$, Tamunodukobipi Daniel Tamuno-Iduabia ${ }^{2}$ and Inegiyemiema Morrison ${ }^{2}$ \\ ${ }^{1}$ Center of Excellence in Marine and Offshore Engineering, Rivers State University, Port Harcourt, Rivers State, Nigeria. \\ ${ }^{2}$ Marine Engineering Department, Rivers State University, Port Harcourt, Rivers State, Nigeria.
}

Global Journal of Engineering and Technology Advances, 2021, 07(01), 019-032

Publication history: Received on 28 February 2021; revised on 02 April 2021; accepted on 05 April 2021

Article DOI: https://doi.org/10.30574/gjeta.2021.7.1.0047

\begin{abstract}
The use of FPSO for deep sea exploration of hydrocarbon resources has been on trend. Thus, there is a need for ensuring safety with regards to station keeping. However, there are mainly two materials used for mooring line fabrication: Synthetic and Steel. Polyester rope is regarded as a good synthetic option for deep water mooring application. This is as a result of its durability in cyclic tensile fatigue loading. This work compares the end forces between the proposed polyester (with top and bottom chains) rope with that of steel-wire rope from existing systems. From the dynamic analysis of the mooring lines with joint criteria for extremes dominated sea states, the maximum value of the end tension for wire rope is $1668.5722 \mathrm{kN}$ of S-1 (Starboard-1) and the total force is $1668.5799 \mathrm{kN}$. Conversely for polyester rope, the maximum value of the end tension is $1130.0381 \mathrm{kN}$ of S-1 and the total force is $1130.0511 \mathrm{kN}$. This result shows that the force and tension in polyester rope are lower than those of steel wire rope: indicating the effects of reduced vertical (gravity) forces of mooring rope on the FPSO with an associated improvement in horizontal restoring force. The substantial decrease in rope weight reduces the complexity of installation, and increases the vessel's payload. The latter enhances its capaciousness for crude oil cargo which consequently boosts its economic viability. Also, the fatigue life of the polyester rope is more than that of steel rope because of its low frequency load.Keywords: Fairlead; Anchor; Returnperiod; Catenary; Taut; Met-ocean; Statics; Dynamics.
\end{abstract}

\section{Introduction}

Over the years, there has been a steady growth in the demand of hydrocarbon products, and this trend is expected to last for more years [1]. To meet up with the demands, operators and designers seek for better ways to hasten development plans. Unfortunately, tremendous amount of oil and gas fields has been discovered offshore where infrastructure is lacking. Different geographical locations and their prevalent environmental conditions have challenged engineers to evolve novel technologies to explore and harness these natural resources in even the remotest parts of the world. This led to the evolution of floating structures such as Floating Production, Storage and Offloading (FPSO) systems which has been one of the most accepted technologies for the developments of remote fields lacking infrastructure [2].

Floating offshore structures, such as FPSOs coupled with mooring lines to the ocean floor (or seabed) experience forces and revolving moments caused by dynamic excitations from environmental elements such as wind, current and waves. To minimize these undesirable motions of FPSOs, it is imperative to anchor them to fixed locations of their operations. However, the anchorage only reduces the effect to a certain safety level. Thus, for the essence of station keeping, systematic analysis must be done to ensure that adequate restoring forces are produced to counter these perturbing environmental forces [1]. The restoring forces from the materials stiffness determine the mooring system required to mitigate excess tension along the lines and prevent riser damage.

\footnotetext{
* Corresponding author: Umana Emediong Christopher

* Center of Excellence in Marine and Offshore Engineering, Rivers State University, Port Harcourt, Rivers State, Nigeria.
} 
The continual migration of oil companies from shallow to deep sea oil exploitations has brought to limelight the significant roles and types of mooring systems. The common types are (a) Catenary (used for shallow waters of about $1000 \mathrm{~m}$ ); and (b) Taut mooring system (used for deep water of about 1000-3000m). For the purpose of this work, catenary mooring system is considered because of cost and shallow-water performance advantages over taut mooring profile. Even though taut has better deep-water performance than catenary, it has limitation in ultra-deep waters [3]. This is because taut is continuously under tension as such could easily snap in the case of extreme weather conditions. For the system to be reliable, a very high-quality material selection and taut integrity are required. This however raises the initial cost or increases the maintenance expenses when it snaps. Proper material selection and system integrity are indicators of a good quality assurance. Nevertheless, catenary profile leaves room for excursion, as such it does not put the lines under continuous tension. Thus, its design service life is longer even with less level of materials integrity.

This work begins with static analysis at preliminary design stage and progresses to dynamic analysis at the final stage. The latter involves distinct combination of various extreme met-ocean conditions for more robust approach and realistic results. This technique aids in designing for worst case scenario. The relative loads of the operational area are derived from data statistics of short- and long-term waves and current characteristics. Following the Lloyd Registers Rules for Floating Offshore Installations at a Fixed Location (FOIFL), the catenary mooring system performance is evaluated with respect to the ambient and extreme environmental conditions of the specific site. The mooring system fatigue analysis is made to reflect a safety level acceptable by the industry.

\section{Statement of Problem}

Wire ropes has long been commonly used for mooring, despite its problem of corrosion. Even with the introduction of polyester rope, which has a near neutral buoyancy when immersed, the effect of corrosion still persists. This wire rope is made up of metal wires merged together to increase its strength and stiffness. Meanwhile, out of the three shown in Figure 1.2, only two (six strands and spiral strands) are considered suitable for offshore mooring. It has a weight relatively lower than chain even though it is generally used with chain (at the top and at the bottom) as shown in Figure 1.1. Also, when compared for the same breaking strength as chain, it has a high level of elasticity. Nevertheless, its disadvantages still outweigh the advantages which are its vulnerability to corrosion and ingress of soil. Wire rope has its cost function ranging from $0.09 /$ Euro $/ \mathrm{KN} / \mathrm{m}$ to $0.02 \mathrm{Euro} / \mathrm{KN} / \mathrm{m}$ with the minimum breaking load as its basis [4].

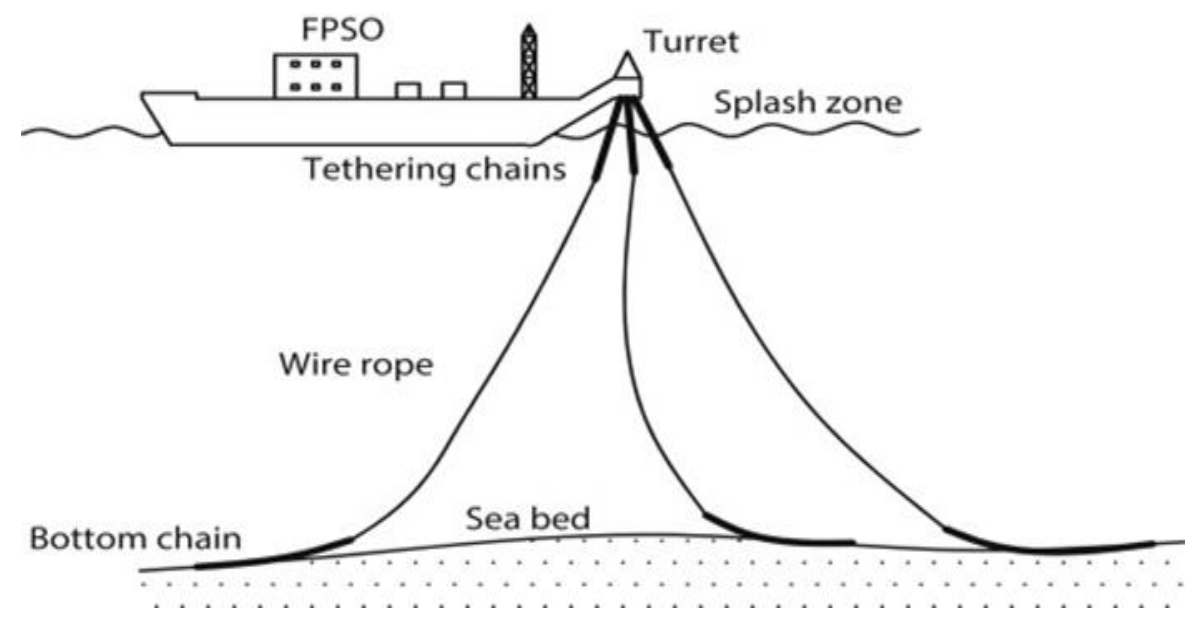

Figure 1 Moored FPSO with Wire Rope Source: [5]

Every oil company has the sole aim of making profit, as such goes way out to reduce cost on anything that will not bring much value or profit to the organization.

Degradation (corrosion), which is one of the key issues with wire rope, cost so much to address. This includes the high costs of corrosion resistant materials; of galvanic coating thickness; high-tech fabrication and installation; and of monitoring and corrosion prevention. The use of zinc for galvanic protection of submerged steel wire mooring ropes could be effective but its duration depends on several parameters including its coating mass. In addition, the zinc must be readily available to go into solution and coupled electrically to the steel, i.e. the electrical continuity of the zinc with the steel can be guaranteed whilst in contact with the seawater electrolyte [7]. 


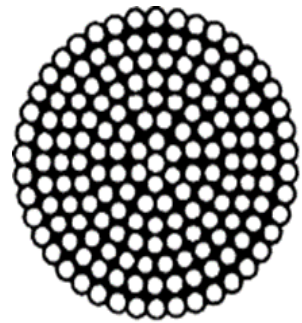

(a) spiral strand

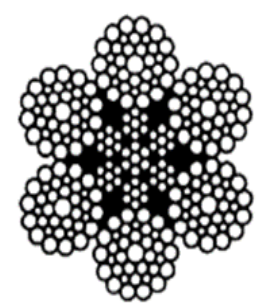

(b) six strand

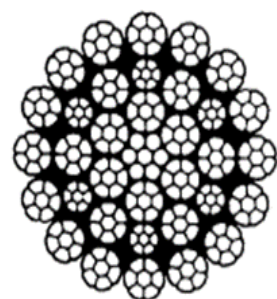

(c) multi-strand

Figure 2 Typical Rope Construction Source: [6]

As the oil exploration shifts gradually from shallow to deep and ultra-deep waters, the issue of corrosion goes on a high side due to the salinity and corrosive nature of the water. Thus, so much attention is required as to reduce both the initial and running cost for galvanic wire coating thickness and corrosion monitors. To solve this problem, polyester rope is suggested as a suitable alternative for the purpose of deep-sea as well as ultra-deep-water mooring. The replacement of wire rope with synthetic fiber rope is an advantage because it addresses the issue of weight. The relative light weight of the synthetic (polyester) fiber rope, when submerged, reduces the entire mooring line weight and polyester has a very good line elasticity.

Nevertheless, the use of synthetic fiber for permanent mooring line has a greater tendency of failure due to fatigue and creep fracture in the rope. This issue occurs mostly in taut mooring profile due to regular tensioning of the line which leads to plastic deformation overtime. In catenary mooring profile, the likely plastic deformation is offset by the excursion allowed in the profile and as such reduces the possibility of tensile failure of the lines.

For cost consideration, synthetic fiber rope ranges from 0.2 Euro/KN $/ \mathrm{m}$ to 0.02 Euro $/ \mathrm{KN} / \mathrm{m}$ with minimum breaking loads as the basis. Considering the use of polyester type of synthetic fiber, the cost function ranges from 0.06 Euro/KN/m to $0.02 \mathrm{Euro} / \mathrm{KN} / \mathrm{m}$ with minimum breaking load as the basis. It is obvious, comparatively, that synthetic fiber is more expensive than wire rope for mooring system. This is deductive because the cost function of polyester rope is obviously lesser than that of wire rope [4].

\subsection{Aim and Objectives of Study}

This dissertation is aimed at designing a catenary mooring system for an FPSO using synthetic fiber (such as polyester) mooring line as a better alternative over the extant steel wire mooring ropes. In order to achieve this aim, the following objectives are considered. These are to:

- $\quad$ Obtain and analyze hydrostatic characteristics of an existing FPSO.

- Gather and evaluate site-specific met-ocean data for the FPSO.

- Determine using computational model the tensions in the mooring lines for statics and dynamic loads.

- Conduct a detailed performance comparison between the proposed polyester line mooring system and that of the extant steel wire-rope mooring system.

\section{Material and methods}

\subsection{Design Consideration}

Every design has its basis which contains several items termed; primary objectives. The primary objectives (of mooring design) is encapsulated as follows:

- To ensure good station keeping of the floating structure within a stipulated tolerance under normal operating and extreme environmental conditions.

- To ensure the excursion of the rigid floater (FPSO) has to be restricted to certain bounds or limit so as not to overstretch the umbilical and risers.

- To offer sufficient fatigue life and sufficient mooring strength to the mooring system so as to ensure the reliability and operability of the offshore system. 


\subsection{Anchor/Mooring Lines}

Mooring lines are mostly in components forms, consisting of several segments which are the chain (Top side), wire rope/polyester/Nylon (lighter cable on the surface of the sea being the middle segment) and chain again (for the bottom section). This helps increase the mooring system's stiffness while obtaining a very much lighter mooring cable system. Figure 3.11 shows an illustration of it.

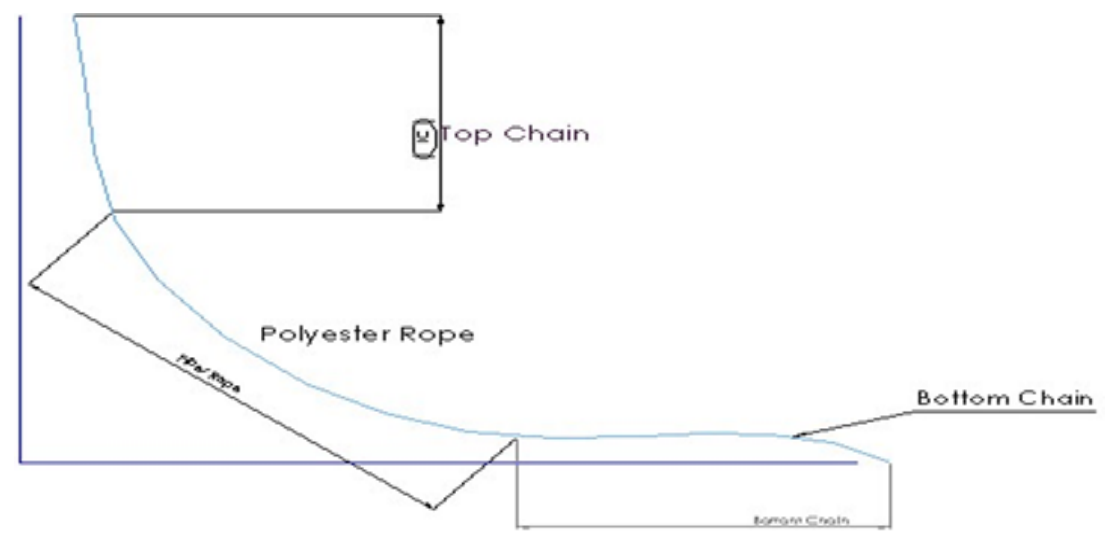

Figure 3 Mooring Line Segment Composition

\subsection{Data Acquisition}

In order to achieve veritable results, a set of reliable in-situ data. The data set acquired includes: the characteristic parameters of the floating structure (FPSO), the operational requirements of the floater and the design environmental conditions. These input parameters are categorized into the following group of data acquired:

\subsubsection{FPSO Particulars}

The particulars of the vessel used as the case study with regards to this research work are shown in the table 1 .

Table 1 Particulars of the Case Study Vessel

\begin{tabular}{|l|l|l|}
\hline Particulars & Ballast & Draught \\
\hline Length Overall & $305.100(\mathrm{~m})$ & $305.100(\mathrm{~m})$ \\
\hline Mass & $161.3 \mathrm{E} 3$ (tons) & $10.00 \mathrm{E} 3$ (tons) \\
\hline Mooring method & Spread Mooring System \\
\hline Mooring Configuration & Catenary \\
\hline Mooring line component & Chain (Top Chain) -Wire-Chain (Bottom Chain) \\
\hline Number of lines & Six (6) \\
\hline
\end{tabular}

\subsubsection{Mooring Line Particulars}

The mooring system is designed to have mooring line length similar to that of Bonga, thus the mid-section line component being wire (in Bonga) was changed to polyester for the purpose of this work. The top end is referred to as the "fairlead, while the bottom is referred to as the "anchor". These are shown in the table 2 and the proposed polyester rope in table 3. 
Table 2 Particulars for Wire Rope

\begin{tabular}{|l|l|l|l|l|}
\hline Portside Line Number & Top Chain (m) & Wire (m) & Bottom Chain (m) & Total Line Length(m) \\
\hline$P-1$ & 101.200 & 1103.000 & 669.600 & 1873.800 \\
\hline$P-2$ & 100.800 & 1104.500 & 671.500 & 1876.800 \\
\hline$P-3$ & 97.700 & 1103.000 & 672.100 & 1872.800 \\
\hline$P-4$ & 93.200 & 1204.600 & 520.400 & 1818.200 \\
\hline$P-5$ & 90.300 & 1201.500 & 521.200 & 1813.000 \\
\hline$P-6$ & 101.200 & 1201.700 & 521.300 & 1824.200 \\
\hline Starboard Line Number & Top Chain (m) & Wire (m) & Bottom Chain (m) & Total Line Length(m) \\
\hline$S-1$ & 96.200 & 1133.600 & 644.500 & 1874.300 \\
\hline S-2 & 97.900 & 1135.600 & 644.900 & 1878.400 \\
\hline$S-3$ & 96.100 & 1135.600 & 646.300 & 1878.000 \\
\hline$S-4$ & 96.000 & 1101.500 & 674.500 & 1872.000 \\
\hline$S-5$ & 102.300 & 1100.500 & 674.400 & 1877.200 \\
\hline$S-6$ & 102.100 & 1101.000 & 675.000 & 1878.100 \\
\hline
\end{tabular}

Table 3 Particulars for Polyester Rope

\begin{tabular}{|l|l|l|l|l|}
\hline Portside Line Number & Top Chain (m) & Polyester (m) & Bottom Chain (m) & Total Line Length (m) \\
\hline$P-1$ & 81.200 & 1103.000 & 669.600 & 1853.800 \\
\hline$P-2$ & 80.800 & 1104.500 & 671.500 & 1856.800 \\
\hline$P-3$ & 77.700 & 1103.000 & 672.100 & 1852.800 \\
\hline$P-4$ & 73.200 & 1204.600 & 520.400 & 1798.200 \\
\hline$P-5$ & 70.300 & 1201.500 & 521.200 & 1793.000 \\
\hline$P-6$ & 81.200 & 1201.700 & 521.300 & 1804.200 \\
\hline Starboard Line Number & & & & \\
\hline$S-1$ & 76.200 & 1133.600 & 644.500 & 1854.300 \\
\hline$S-2$ & 77.900 & 1135.600 & 644.900 & 1858.400 \\
\hline$S-3$ & 76.100 & 1135.600 & 646.300 & 1858.000 \\
\hline$S-4$ & 76.000 & 1101.500 & 674.500 & 1852.000 \\
\hline$S-5$ & 82.300 & 1100.500 & 674.400 & 1857.200 \\
\hline$S-6$ & 82.100 & 1101.000 & 675.000 & 1858.100 \\
\hline
\end{tabular}

\subsubsection{Mooring line geometry and mass}

The geometry and mass of the site in situ mooring lines data are shown in the table 4 . 
Wire Rope Geometry

Table 4 Geometry and Mass of Each Wire Mooring Lines

\begin{tabular}{|l|l|l|l|l|}
\hline $\mathbf{S} / \boldsymbol{N}$ & Name & Inner Diameter $(\boldsymbol{m})$ & Outer Diameter $(\boldsymbol{m})$ & Mass per Unit Length (ton/m) \\
\hline 1 & P1-6Top chain & 0.1780 & 0.0000 & 0.1960 \\
\hline 2 & P1-6 Wire rope & 0.1030 & 0.0000 & 0.0440 \\
\hline 3 & P1-6 Bottom chain & 0.1670 & 0.0000 & 0.1710 \\
\hline 4 & S1-3 Top chain & 0.1780 & 0.0000 & 0.1960 \\
\hline 5 & S1-3 Wire rope & 0.0960 & 0.0000 & 0.0390 \\
\hline 6 & S1-3 Bottom chain & 0.1780 & 0.0000 & 0.1960 \\
\hline 7 & S4-6 Top chain & 0.1780 & 0.0000 & 0.1960 \\
\hline 8 & S4-6 Wire rope & 0.0960 & 0.0000 & 0.0390 \\
\hline 9 & S4-6 Bottom chain & 0.1670 & 0.0000 & 0.1710 \\
\hline
\end{tabular}

Polyester Rope Geometry

The diameter for the wire ropes (6x19 wire rope with IWC) and minimum breaking load (MBL) (as drawn from wire rope catalogue in appendix $\mathrm{Y}$ ) are:

$$
\begin{aligned}
\text { for } & \mathrm{P} 1-6=0.103 \mathrm{~m} \mathrm{MBL}=7050 \mathrm{KN} \\
\text { and } & \mathrm{S} 1-6=0.096 \mathrm{~m} \mathrm{MBL}=6270 \mathrm{KN}
\end{aligned}
$$

These MBL values were checked for corresponding diameter and the submerged weight per unit meter for polyester rope in appendix $Z$. The exact values were not found on the table as such, the diameter and submerged weight per unit meter of polyester rope for the corresponding MBLs were found by interpolation. Thus, the new diameter for the polyester rope were:

$\mathrm{P} 1-6=0.159 \mathrm{~m}$

$\mathrm{S} 1-6=0.152 \mathrm{~m}$

Table 5 Geometry and Mass of Each Polyester Mooring Lines

\begin{tabular}{|l|l|l|l|l|}
\hline $\boldsymbol{S} / \boldsymbol{N}$ & Name & Inner Diameter $(\boldsymbol{m})$ & Outer Diameter $(\boldsymbol{m})$ & Mass per Unit Length (ton/m) \\
\hline 1 & P1-6 Top chain & 0.1780 & 0.0000 & 0.1960 \\
\hline 2 & P1-6 Polyester rope & 0.1590 & 0.0000 & 0.0041 \\
\hline 3 & P1-6 Bottom chain & 0.1670 & 0.0000 & 0.1710 \\
\hline 4 & S1-3 Top chain & 0.1780 & 0.0000 & 0.1960 \\
\hline 5 & S1-3 Polyester rope & 0.1520 & 0.0000 & 0.0036 \\
\hline 6 & S1-3 Bottom chain & 0.1780 & 0.0000 & 0.1960 \\
\hline 7 & S4-6 Top chain & 0.1780 & 0.0000 & 0.1960 \\
\hline 8 & S4-6 Polyester rope & 0.1520 & 0.0000 & 0.0036 \\
\hline 9 & S4-6 Bottom chain & 0.1670 & 0.0000 & 0.1710 \\
\hline
\end{tabular}




\subsection{Environmental Data}

In order to perform the dynamic analysis, the met-ocean parameters containing various sea states and conditions, has to be used. The table 6 shows the condition of the seabed.

Table 6 Seabed Condition

\begin{tabular}{|l|l|l|}
\hline S/N & Seabed Depth $(3 D)(\boldsymbol{m})$ & $\mathbf{1 0 2 5 . 5 0}$ \\
\hline 1 & Sea Temperature $\left({ }^{\circ} \mathrm{C}\right)$ & 10.00 \\
\hline 2 & Kinematic Viscosity $\left(\mathrm{m}^{\wedge} 2 / \mathrm{s}\right)$ & $3.5 \%$ Salinity \\
\hline 3 & Sea Density (ton $\left./ \mathrm{m}^{\wedge} 3\right)$ & 1.025 \\
\hline
\end{tabular}

\subsubsection{Joint met-ocean design criteria}

The predominant sea state used for mooring line analysis is the joint criteria for extremes dominated by squall. Squalls are short duration (20-30 minutes) extreme wind speeds with occurrence in a lesser degree in February-March and larger degree in April-June and October-November. However, they still generate significant wind sea. The associated swell height during this period is obtained from the average swell height which is $1.25 \mathrm{~m}$. It should be noted that no evidence has been found that currents can be generated by squalls as such, currents are treated as being independent of the squalls. So therefore, the associated currents are the mean currents obtained in February-June and OctoberNovember, when squalls occur typically.

\subsection{Analysis of The Mooring Lines}

\subsubsection{Load mechanism}

The load induced on the mooring lines is divided into two:

Static loads: Which means the load is just there and these loads does not change overtime. It requires less factor of safety than dynamic loading.

Dynamic loads: These are environmental loads which are wave, wind and current. These loads are always considered from about 100 to 10,000 years return period, which is enough to simulate the dynamics nature of our environment at its extreme condition. its equation could be written out below as;

F Environment $=$ F Wave + F wind + F Current

\subsection{Analytical Catenary Representation}

The static analysis of the loads induced on the lines is carried out using catenary equations computed on an Excel sheet and verified with Orcaflex. However, the analysis of mooring lines in iterative. In such case, you will only need the following parameters; the weight per unit meter of the mooring line, water depth ( which could be taken to be the vertical distance from the fairleads to the touchdown point) and the horizontal tension (which is at first assumed iteratively in order to have the desired mooring line length). These values are used in the following equations to derive step out distance, suspended line length and vertical component of tension:

3.6.1. Definition of parameters:

$$
\begin{gathered}
\mathrm{x}=\mathrm{T}_{-} \mathrm{H} / \mathrm{W} \cosh ^{\wedge}(-1)\left[\left(\left(\mathrm{w}^{*} \mathrm{~h}\right) / \mathrm{T}_{-} \mathrm{H}\right)+1\right] \\
\mathrm{s}=\mathrm{T}_{-} \mathrm{H} / \mathrm{W} \sinh \left[\left(\left(\mathrm{w}^{*} \mathrm{x}\right) / \mathrm{T}_{-} \mathrm{H}\right)\right. \\
\mathrm{T}_{-} \mathrm{v}=\mathrm{w}^{*} \mathrm{~h}
\end{gathered}
$$

Where; $\mathrm{x}=$ The step out distance

$\mathrm{h}=$ Vertical dimension (depth)

$\mathrm{s}=$ Line length 
$\mathrm{w}=$ Weight per unit length of mooring line in water

$\mathrm{T}(\mathrm{v})=$ Vertical component of tension

With these values gotten, it is being used in Orcaflex using the line setup wizard to iteratively derive a suitable mooring line length.

Nevertheless, the equations stated further could be used since the tension similar to that of the existing system is to be achieved. Here, the equations consider the line as a single continuous object with no discretization into subsequent nodes. The top tension ( $\mathrm{T}$ ) is used with the angle it makes with the water line to obtain the horizontal tension, before proceeding to obtain the other variables. However, this analytic representation doesn't consider dynamic effects. Thus, it only predicts the static configuration of the line. The illustration is shown in Figure 3.1

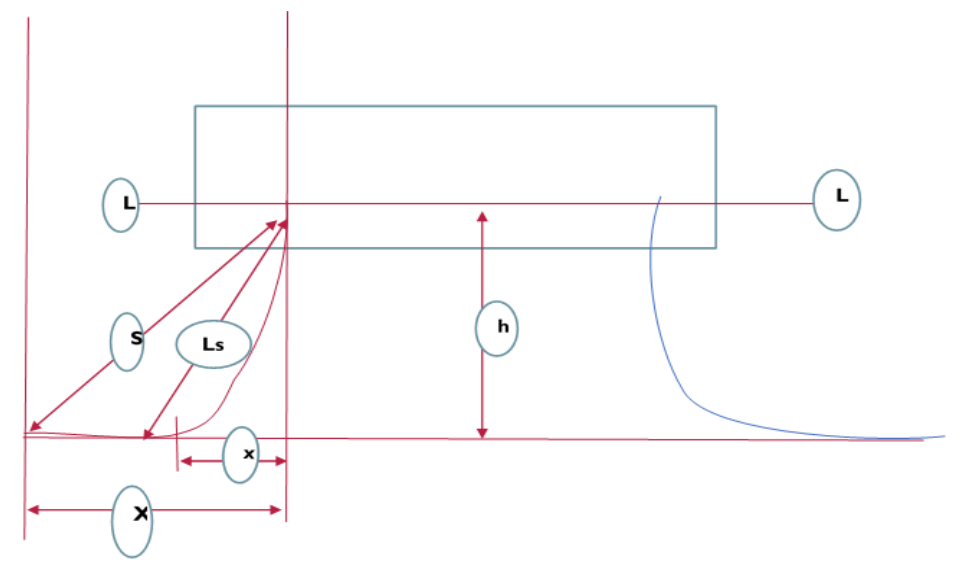

Figure 4 Schematic Diagram of the Mooring System with FPSO.

3.6.2. Definition of parameters

Horizontal tension

Horizontal dimension

Suspended line length

Step out distance

Vertical dimension (depth)

Merging equation 3.7 to 3.8 we have

The line tension at the top (of the platform)

Maximum tension

Total line length

Safety condition

Where $\mathrm{a}=$ Horizontal dimension

$\mathrm{h}=$ Vertical dimension (depth)

$\mathrm{x}=$ Step out distance

$\mathrm{X}=$ Horizontal distance from the anchor point to the fairleads

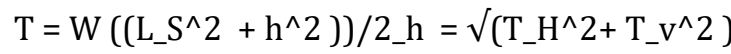

T_max $=\mathrm{T}_{-} \mathrm{H}+\mathrm{Wh}$

$\mathrm{X}=\mathrm{s}-\mathrm{Ls}+\mathrm{X}$

T_max $\leq$ T_mbl 
Ls = Suspended line length

$\mathrm{T}_{-} \mathrm{H}=$ Horizontal restoring force (applied by the mooring line)

$\mathrm{T}=$ Tension at the top

T_max $=$ Maximum tension

T_mbl = Minimum breaking load

$\mathrm{T}_{-}(\mathrm{v})=$ Vertical component of tension

$\mathrm{W}=$ Weight per unit length of mooring line in water

$\theta \_\mathrm{W}=$ Angle of tension at the mean sea level

N/B: some aspects that are not accounted for in the analytical representation are Inertia, added mass, bending stiffness, pressure effect, torsional stiffness, drag and end connection stiffness.

\subsection{Dynamic Analysis of Mooring Line System}

To carry out the dynamic analysis of the mooring system, the understanding of the floating structure itself, the medium in which the structure floats, the environment loads (wind, wave and current) and the lines used in keeping the structure at a static position has to be modelled mathematically. The dynamic equation is being presented thus:

$$
M\left[X^{*}\right]+C\left[X^{*}\right]+K[X]=F(t)
$$

Where: $\mathrm{M}=$ Mass of the body

$\mathrm{K}=$ Spring stiffness

$\mathrm{C}=$ Line damping coefficient

$\mathrm{F}(\mathrm{t})=$ Environmental loads (wind, wave, drift-force and current)

This equation considers the load factors that changes with time. It calculates the entire force exerted on the structure (mooring line) over a certain period of time. This is thereafter used in the design consideration.

\subsection{MBL of Polyester}

The MBL and diameter of the wire rope is used to interpolate for that of the polyester rope. This is done by using the same MBL of the wire rope to get a diameter for the polyester rope at similar MBL. The diameter for the wire rope is:

Diameter

$$
\begin{gathered}
P(1-6)=0.103 \mathrm{~mm} \quad \mathrm{MBL}=7050 \mathrm{kN} \\
\mathrm{S}(1-6)=0.096 \mathrm{~mm} \mathrm{MBL}=6270 \mathrm{kN}
\end{gathered}
$$

From polyester rope catalogues (Bridon-FiberRope-Catalogue, 2020);

Table 7 Rope values from catalogue, For P (1-6)

\begin{tabular}{|l|l|}
\hline Diameter $(\mathrm{mm})$ & MBL $(\mathrm{kN})$ \\
\hline 158 & 6959 \\
\hline $\mathrm{X}$ & 7050 \\
\hline 168 & 7848 \\
\hline \multicolumn{2}{|l|}{ Upon interpolation $\mathrm{x}=0.1590 \mathrm{~mm}$}
\end{tabular}

Table 8 Rope values from catalogue, For S (1-6)

\begin{tabular}{|l|l|}
\hline Diameter $(\mathrm{mm})$ & MBL $(\mathrm{kN})$ \\
\hline 151 & 6180 \\
\hline $\mathrm{X}$ & 6270 \\
\hline 158 & 6958 \\
\hline
\end{tabular}




\subsection{Axial Stiffness}

The axial stiffness for the polyester rope is derived from the load-extension graph of Figure 3.2 as thus;

$$
\epsilon=\left(\mathrm{F}^{*} \mathrm{~L}\right) /\left(\mathrm{A}^{*} \Delta \mathrm{L}\right)
$$

Note: $\mathrm{F} \approx \mathrm{MBL}$

$$
\mathrm{A} \epsilon=\left(\mathrm{F}^{*} \mathrm{~L}\right) / \Delta \mathrm{L}
$$

The Axial Stiffness which is $A \epsilon=\left(F^{*} \mathrm{~L}\right) / \Delta \mathrm{L}$ at $100 \%$ Load (i.e. MBL which is $\approx 100 \% \mathrm{~F}$ ) is read from the graph (Figure 3.2 ) to be $12 \%$ Extension.

Extension $(\%)=\left(\Delta \mathrm{L}^{*} 100\right) / \mathrm{L}$, which means at $100 \%$ load $(\%)$, the equation resolves to $12=\left(\Delta \mathrm{L}^{*} 100\right) / \mathrm{L}$

$$
\begin{aligned}
& \Delta \mathrm{L}=0.12 \mathrm{~L} \\
& \mathrm{~L}=\Delta \mathrm{l} / 0.12
\end{aligned}
$$

Substituting equation 3.15 for $\Delta \mathrm{L}$ in equation 3.14 , the axial stiffness becomes;

$$
\mathrm{A} \epsilon=\mathrm{MBL} /(0.12)
$$

Which means that at $100 \%$ of load, there will be $12 \%$ extension. However, it should be noted that this for other values of load (\%) and the axial stiffness will similarly reduce when compared to that of the wire rope.

So, at MBL for $\mathrm{P}(1-6)$ which is $7050 \mathrm{kN}$,

$$
\mathrm{A} \epsilon=(7050(\mathrm{KN})) /(0.12)=58750 \mathrm{kN}
$$

and at $S(1-6)$,

$$
\mathrm{A} \epsilon=(6270(\mathrm{KN})) /(0.12)=52250 \mathrm{kN}
$$

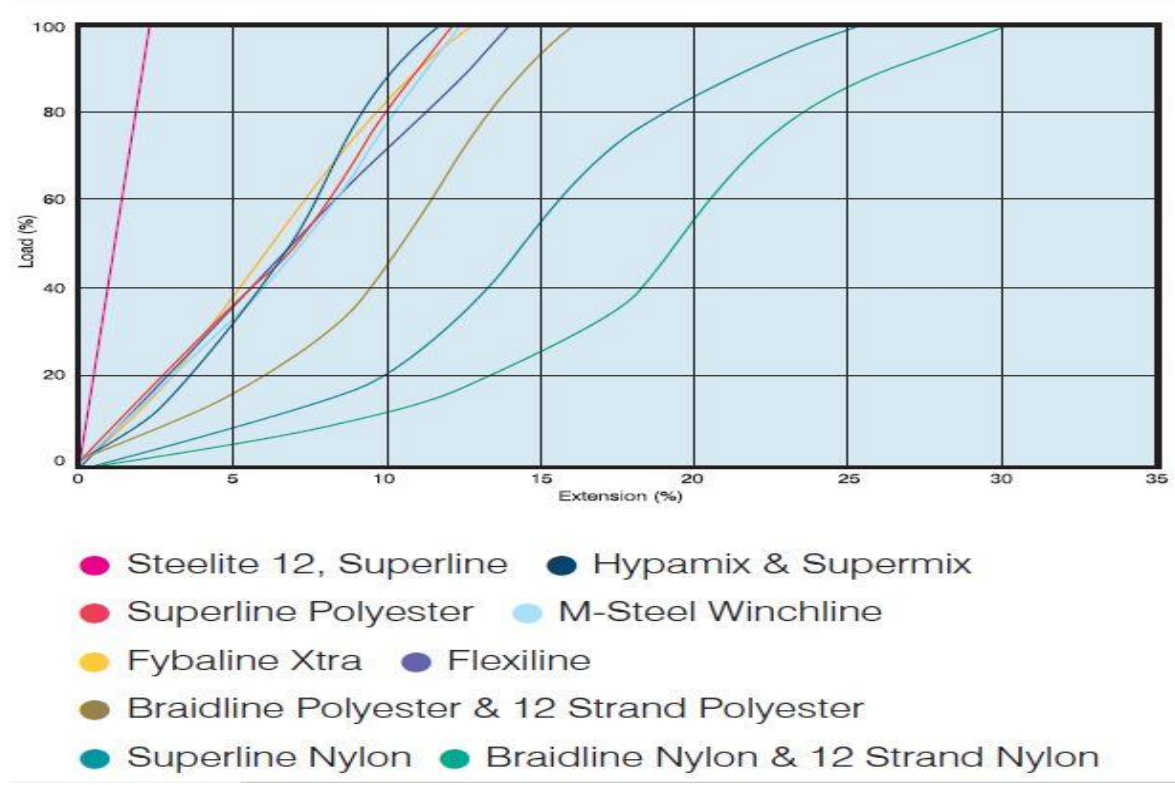

Figure 5 Load Extension Source: [8] 


\section{Results and discussion}

\subsection{Mooring Strength Criteria}

The mooring system is designed such that it is capable of withstanding extreme environmental loads and the strength requirements are being met by all the components of the mooring line. During the design, strength analysis of the mooring line was done in order to predict the tensions (this is further discussed in detail below) in the mooring lines under extreme environment of an explicit return period. The return period used, otherwise known as recurrence period which is an estimate of the likelihood of event occurrence e.g. swell, squall etc., was a 100-year return period. This means that the event is expected to occur on an average of once every 100 years.

\subsection{Dominant Environment}

After performing the static analysis of the model with the use of Orcaflex, a dynamic analysis was further performed. The dynamic analysis of the model files (wire and polyester rope) was performed with the combination of wind (squall) dominant sea states which included (windsea, swell, squall and current) at different directional angles. It was reaffirmed that the sea state direction with predominant force effects (i.e. highest mooring line tension) was squall.

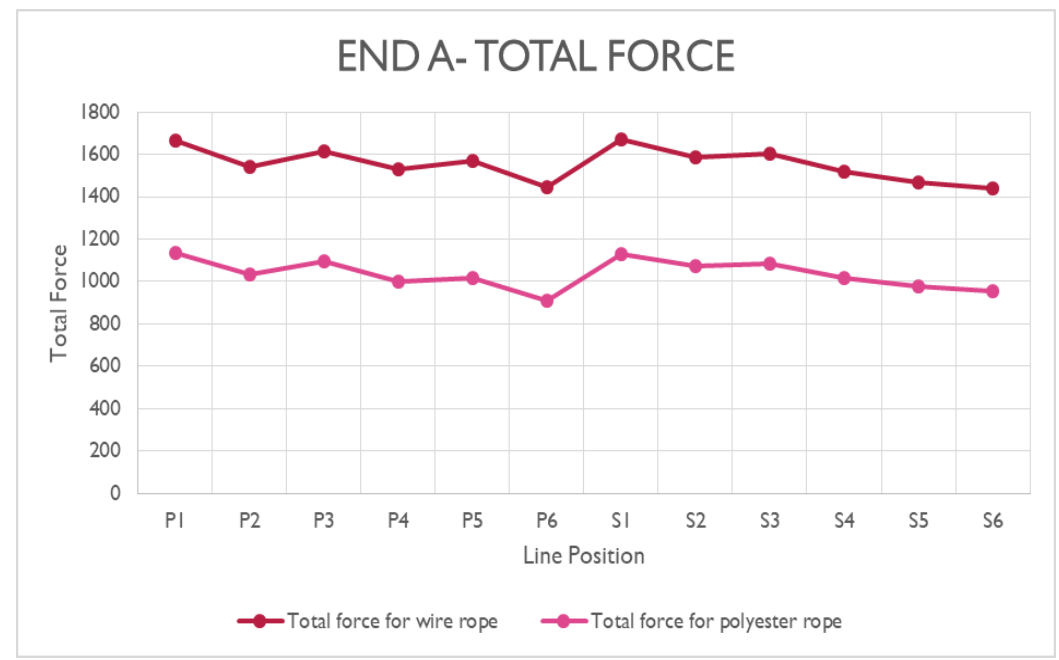

Figure 6 Line graph showing the plot of total force to line position at the fairlead (End A)

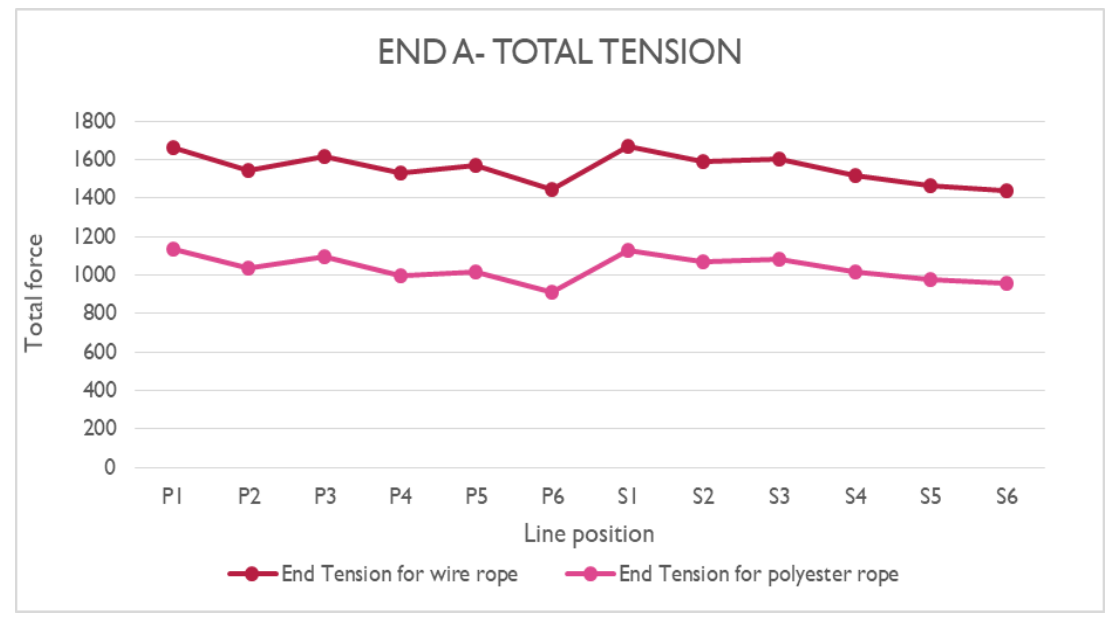

Figure 7 Line graph showing the plot of End Tension to line position at the fairlead (End A) 


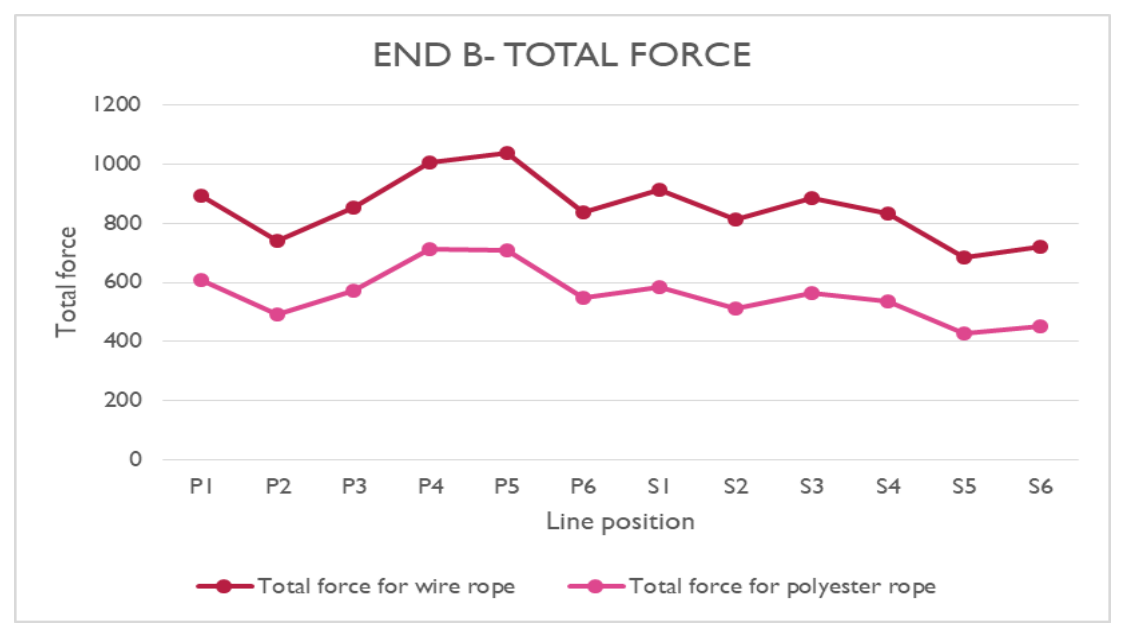

Figure 8 Line graph showing the plot of Total Force to line position at the Suction Pile (End B)

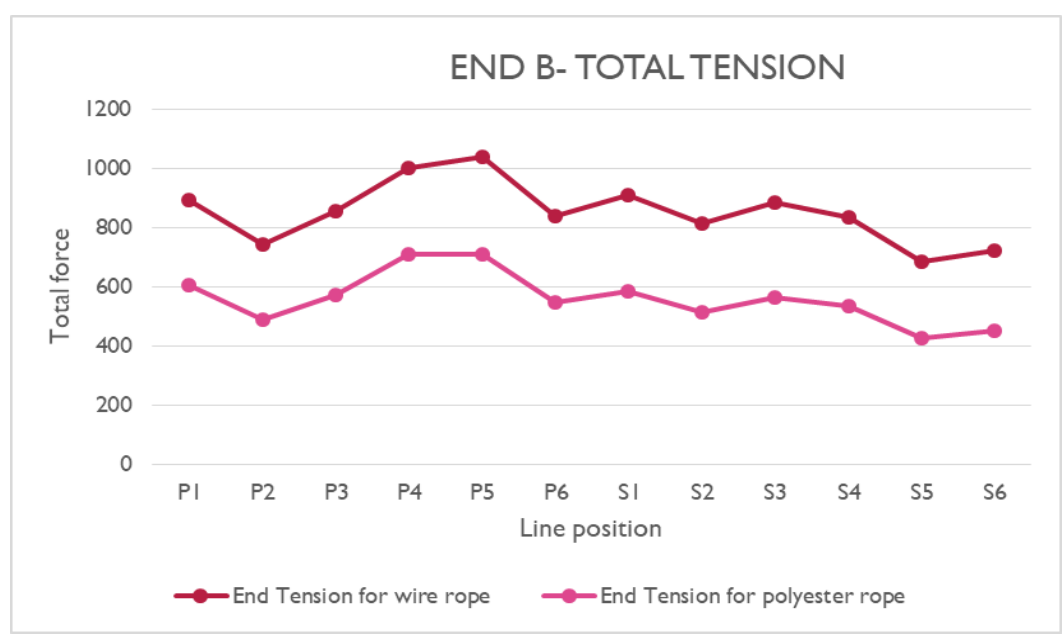

Figure 9 Line graph showing the plot of End Tension to line position at the Suction Pile (End B)

\subsection{Mooring Strength}

The bar chats shown from Figure 4.1 to 4.4, it is obvious that the values for both the total force and end tension for the polyester rope is less than that of wire rope. However, more details of the result gotten from these lines analysis could be seen in Appendix A - X, but from the bar charts for total forces, the lines are compared and analyzed below;

\subsubsection{Total forces on lines}

Wire rope: The maximum value of the end tension for wire rope is $1668.5722 \mathrm{kN}$ of S-1 and the total force is 1668.5799 $k N$.

Polyester rope: The maximum value of the end tension for polyester rope is $1130.0381 \mathrm{kN}$ of S-1 and the total force is $1130.0511 \mathrm{kN}$.

The table which makes up the appendices, is drawn from the statics and dynamics analysis result summary of the Orcaflex "sim" file for both the wire rope and the proposed polyester rope. It should be noted that point " $A$ " is the point of fairlead attached to the FPSO while point "B" is the point moored to the suction pile on the seabed. It should also be noted that the two rope had the same length and only the mid-section of the wire rope (chain-wire combination) was replaced with the polyester rope under the same dynamic environmental load. 
It is obvious that the strength of the Total force on the wire rope under static and dynamic loads is much higher than that of polyester rope. Due to the lesser weight of the polyester which is obviously from the lesser top end tension, the downward vertical pull of the FPSO is reduced thus increasing the payload of the structure.

\subsubsection{Diameter and $M B L$ of polyester rope}

From chapter three, section 3.8 (table 3.6 \&3.7), it is obvious that at similar $M B L$, the diameter of the rope increases for polyester rope. This can easily be said that for a particular $M B L$ of wire rope, an equivalent stiffness can be obtained for polyester rope by increasing the diameter of the polyester rope.

\subsubsection{Weight per unit meter of polyester rope}

At similar MBL of wire rope, the weight per unit length of polyester rope decreases by $9.3 \%-9.4 \%$. This could be seen in table 3.5 as deduced from appendix $\mathrm{Z}$.

\subsubsection{Axial stiffness}

From chapter three, section 3.9, the axial stiffness for wire ropes with wire core is $4.04 \times 10^{7} \mathrm{~d}^{2} \mathrm{kN}$, which is 4.161200 $\mathrm{x} 10^{6} \mathrm{kN}$ for line $\mathrm{P}(1-6)$ and $3.878400 \times 10^{6} \mathrm{kN}$ for line $\mathrm{S}(1-6)$. This shows that the axial stiffness for polyester rope at the same MBL to that of wire rope (when deduced from figure 3.3) is much lower. This results in low load amplitude at wave frequency i.e. it has less frequency loads amplitude when compared with wire ropes. This reduces the potential of resonance occurrence (where the wave period is not equal to the natural period of the mooring system).

\subsubsection{Creep}

Polyester mooring ropes in mooring applications when loaded normally, are not subjected to or does not experience significant creep. Thus, in the mooring design, creep rupture or creep analysis is not needed. However, the adjustment of the mooring line during the design life of the rope due to rope creep and adequate top chain segment should be reserved to aid future line readjustment

\section{Conclusion}

When comparing polyester to wire ropes, polyester ropes have less axial stiffness. Thus, it is obvious that the proposed system has very small/less load frequency. This reduces the potential of resonance occurrence which would reduce the rope's life.

At the same minimum breaking load with that of wire rope, the weight per unit length of polyester rope is reduced by $10 \%$ of that of wire rope. This decrease in weight enhances ease of installation (reduce complexity during installation) and also increases payload, which is economical as it reduces cost.

Potential problems like creep has been evaluated from previous studies and found not to appear significantly. However, creep deformation due to operation will be concentrated in early life and should be considered when seizing the steel component (top and bottom chain). Polyester rope is not affected by axial compression fatigue.

\section{Compliance with ethical standards}

\section{Acknowledgments}

I thank God who has made this work a success, through the thick and thin, His soothing touches kept me going.

So much thanks to the Director Center of Excellence Marine and Offshore Engineering, for being a good leader, mentor and father to every one of us who have participated in this program.

I also want to appreciate my academic supervisors, Dr. Daniel Tamunodukobipi and Engr. Morrison * Inegiyemiema who has been of tremendous help towards the success of this work.

\section{Disclosure of conflict of interest}

All authors would like to declare that there is no conflict of interest relevant to this article. 


\section{References}

[1] Lee MY. Design and Regulatory Consideration (American Bureau of Shipping). 5-8 May 1997.

[2] Kai Tung Ma YL. Mooring System Engineering for Offshore Structures. Elsevier. 2019.

[3] Wang TY, Li JY, Xu Z, Liu JK. Design and Comparison of Catenary and Taut Mooring Systems for New Concept FPSO IQFP in Shallow Waters. 08 June, 2013,

[4] Hammoutene AG. Offshore Mooring Line. Retrieved 02 April, 2020, from Offshore Consulting Engineering. 2006.

[5] Yaghin AL, Melchers RE. Long-term inter-link wear of model mooring chains. Elsevier. 29 August 2015.

[6] Chaplin C. Torsional failure of a wire rope mooring line during installation in deep water, Failure Analysis Case. 13 February 2013; II: 45-60.

[7] Chaplin CR, Potts EA, Curtis A. Degradation of wire rope mooring lines in SE Asian waters. OFFSHORE ASIA. researchgate. 2008; 21.

[8] Bridon-FiberRope-Catalogue. Bridon-FiberRope-Catalogue. 11-28. 2020. 